\title{
Nondestructive and Complete Analysis of Magnetite-Maghemite Solid Solutions by a Combined X-Ray Diffraction/Fluorescence Method
}

\author{
Masaaki Iwatsuki and Tsutomu FuKaSawa \\ Department of Applied Chemistry and Biotechnology, Faculty of Engineering, Yamanashi University, \\ Takeda, Kofu 400, Japan
}

\begin{abstract}
This paper describes a nondestructive and complete analysis of magnetite $\left(\mathrm{FeO} \cdot \mathrm{Fe}_{2} \mathrm{O}_{3}\right)$-maghemite $\left(\gamma\right.$ - $\left.\mathrm{Fe}{ }_{2} \mathrm{O}_{3}\right)$ solid solutions including minor constituents: the proposed method consists of measurements of the lattice constant and X-ray fluorescent determination of the minor constituents. The diffraction angles of the solid solution were corrected using a silicon internal standard for calculation of the lattice constant, $a_{0}$. Intensity ratios of $\mathrm{Mn} \mathrm{K}_{\alpha} / \mathrm{Fe} \mathrm{K}_{\alpha}$ and $\mathrm{Zn} \mathrm{K}_{\alpha} / \mathrm{Fe} \mathrm{K}_{\alpha}$ were measured for the determination of manganese and zinc and for the correction of the lattice constant due to the minor elements. The final analysis was done using the linear relation between $a_{0}$ and the sum total of converted mole percentages of divalent metal oxides. Differences between the analytical results obtained by the present method and those obtained by the wet methods were within $3.4 \mathrm{wt} \%$ for $\mathrm{Fe}_{2} \mathrm{O}_{3}$, within $1.5 \mathrm{wt} \%$ for $\mathrm{FeO}$, and within $0.08 \mathrm{wt} \%$ for $\mathrm{MnO}$ and $\mathrm{ZnO}$. Time required for a complete analysis is about $30 \mathrm{~min}$.
\end{abstract}

Keywords Magnetite, maghemite, solid solution, lattice constant, X-ray diffraction analysis, X-ray fluorescence analysis, manganese, zinc

In the previous paper ${ }^{1}$, the authors have reported a linear relation between the mole percentage of $\mathrm{Fe}_{2} \mathrm{O}_{3}$ or the sum total of mole percentages of divalent metal oxides in magnetite $\left(\mathrm{FeO} \cdot \mathrm{Fe}_{2} \mathrm{O}_{3}\right)$-maghemite $\left(\gamma-\mathrm{Fe}_{2} \mathrm{O}_{3}\right)$ solid solutions and their lattice constants corrected for contents of minor constituents, $\mathrm{MnO}$ and $\mathrm{ZnO}$. The present paper describes the use of the linear relation for a nondestructive and complete analysis of the solid solutions: the proposed method consists of measurements of the lattice constant and X-ray fluorescent (XRF) intensity ratios of $\mathrm{Mn} \mathrm{K}_{\alpha} / \mathrm{Fe} \mathrm{K}_{\alpha}$ and $\mathrm{Zn} \mathrm{K}_{\alpha} / \mathrm{Fe} \mathrm{K}$ for the determination of the minor elements and for the correction of lattice constant according to their contents. The determination of $\mathrm{Fe}_{2} \mathrm{O}_{3}$ and $\mathrm{FeO}$ has been done so far only by wet methods ${ }^{2}$ which require delicate techniques and are time-consuming and tedious, as is well known. Qualitative state analyses also have been studied before; for instance, Kanazawa et al. ${ }^{3}$ studied the relationship between the oxidation number of iron and the chemical shift of the $\mathrm{Fe} \mathrm{K}_{\beta 1,3}$ line from synthetic magnetite, maghemite and various ferrites by using a two-crystal type X-ray spectrometer; Mössbauer spectrometry also has been applied to the studies on iron oxides, for instance, photoelectrode ${ }^{4}$ and films. ${ }^{5}$ The proposed method, however, is quantitative, rapid and nondestructive. It is also a very unique method combining X-ray diffraction (XRD) analysis with XRF analysis.

\section{Experimental Background}

The lattice constant, $a_{\mathrm{c}}$, which was corrected with contents of minor constituents, $\mathrm{MnO}$ and $\mathrm{ZnO}$, has been found ${ }^{1}$ to be represented by Eq. (1):

$$
\begin{aligned}
a_{\mathrm{c}} & =a_{y}+S X_{\mathrm{Fe} 2 \mathrm{O} 3} \\
& =a_{y}+S_{\mathrm{a}}\left(X_{\mathrm{FeO}}+X_{\mathrm{MnO}}+X_{\mathrm{ZnO}}\right)
\end{aligned}
$$

where $a_{y}$ is the lattice constant of $\gamma-\mathrm{Fe}_{2} \mathrm{O}_{3} ; X_{\mathrm{Fe} 2 \mathrm{O} 3}, X_{\mathrm{FeO}}$, $X_{\mathrm{MnO}}$, and $X_{\mathrm{Zno}}$ are mole percentages of oxides shown by sufix; $S$ and $S_{\mathrm{a}}$ are the slopes of plots of $a_{\mathrm{c}} v s$. mole percentage of $\mathrm{Fe}_{2} \mathrm{O}_{3}$ and $a_{\mathrm{c}}$ vs. sum total of mole percentages of divalent metal oxides, respectively.

This leads to the possibility that measurements of the lattice constant may reveal the contents of $\mathrm{Fe}_{2} \mathrm{O}_{3}$ and also $\mathrm{FeO}$ in the solid solution, provided that the contents of minor divalent metal oxides are known. If the XRF method allows the rapid and nondestructive determinations of minor divalent metals such as $\mathrm{Mn}$ and $\mathrm{Zn}$ in the samples, the combined XRD/XRF method will allow the nondestructive and rapid determination of $\mathrm{Fe}_{2} \mathrm{O}_{3}, \mathrm{FeO}$, and minor constituents such as $\mathrm{MnO}$ or $\mathrm{ZnO}$.

Equation (1) can be transformed into Eq. (2), representing the observed lattice constant, $a_{0}$, for convenience in practical use:

$$
\begin{aligned}
a_{0} & =a_{y}+S_{\mathrm{a}}\left(X_{\mathrm{FeO}}+c_{\mathrm{MnO}} X_{\mathrm{Mno}}+c_{\mathrm{Zno}} X_{\mathrm{zno}}\right) \\
& =a_{y}+S_{\mathrm{a}}\left(X_{\mathrm{FeO}}+2.84 X_{\mathrm{MnO}}+1.80 X_{\mathrm{Zno}}\right)
\end{aligned}
$$


where $c_{\mathrm{MnO}}$ and $c_{\mathrm{ZnO}}$ are conversion factors of $X_{\mathrm{Mno}}$ and $X_{\mathrm{ZnO}}$, respectively: the factors express the magnitude of the effect of their replacements on the lattice constant. Namely, $c_{\mathrm{MnO}} X_{\mathrm{Mno}}$ and $c_{\mathrm{Zno}} X_{\mathrm{Zno}}$ are "converted mole percentage" for each constituent, and $\left(X_{\mathrm{FeO}}+c_{\mathrm{MnO}} X_{\mathrm{MnO}}+\right.$ $\left.c_{\mathrm{zno}} X_{\mathrm{zno}}\right)$ means "total mole percentage converted as $\mathrm{FeO}$ ". The factors were calculated from the following equations using the lattice constants of magnetite $(8.3967 \AA)^{6}$, maghemite $(8.341 \AA)^{7}$, jacobsite $\left(\mathrm{MnO} \cdot \mathrm{Fe}_{2} \mathrm{O}_{3}\right.$, $8.499 \AA)^{8}$ and franklinite $\left(\mathrm{ZnO} \cdot \mathrm{Fe}_{2} \mathrm{O}_{3}, 8.4411 \AA\right):{ }^{9}$

$$
\begin{aligned}
& c_{\mathrm{MnO}}=\left(a_{\mathrm{MnO} \cdot \mathrm{Fe} 203}-a_{y}\right) /\left(a_{\mathrm{FeO} \cdot \mathrm{Fe} 2 \mathrm{O} 3}-a_{y}\right)=2.84 \\
& c_{\mathrm{ZnO}}=\left(a_{\mathrm{ZnO} \cdot \mathrm{Fe} 2 \mathrm{O} 3}-a_{y}\right) /\left(a_{\mathrm{FeO} \cdot \mathrm{Fe} 2 \mathrm{O} 3}-a_{y}\right)=1.80 .
\end{aligned}
$$

On the other hand, XRF analysis is expected to give linear relations between the $\mathrm{K}_{\alpha}$ intensity ratios, $R_{\mathrm{Mn}}$ and $R_{\mathrm{Zn}}$, of minor constituents $\mathrm{Mn}$ and $\mathrm{Zn}$ against the main constituent $\mathrm{Fe}$ and their mole ratios. And the following relations may be obtained:

$$
\begin{aligned}
& R_{\mathrm{Mn}}=S_{\mathrm{Mn}} X_{\mathrm{MnO}} /\left(2 X_{\mathrm{Fe}^{2 O 3} 3}+X_{\mathrm{FeO}}\right) \\
& R_{\mathrm{Zn}}=S_{\mathrm{Zn}} X_{\mathrm{ZnO}} /\left(2 X_{\mathrm{Fe} 203}+X_{\mathrm{FeO}}\right)
\end{aligned}
$$

where $S_{\mathrm{Mn}}$ and $S_{\mathrm{Zn}_{\mathrm{n}}}$ are the slopes of plots of $R_{\mathrm{Mn}}$ or $R_{\mathrm{Zn}} v s$. the mole ratios shown.

Furthermore, the sum total of mole percentages of all constituents should be equal to 100 :

$$
X_{\mathrm{Fe} 2 \mathrm{O} 3}+X_{\mathrm{FeO}}+X_{\mathrm{MnO}}+X_{\mathrm{ZnO}}=100 \text {. }
$$

The mole percentages of the oxides can be obtained by solving Eqs. (2) - (5) as follows:

$$
\begin{aligned}
& X_{\mathrm{Fe} 203}=(A+A B-100 C-100) /(C-2 B-1) \\
& X_{\mathrm{FeO}}=(200 C-A-2 A B) /(C-2 B-1) \\
& X_{\mathrm{MnO}}=R_{\mathrm{Mn}}(A-200) / S_{\mathrm{Mn}}(C-2 B-1) \\
& X_{\mathrm{ZnO}}=R_{\mathrm{Zn}}(A-200) / S_{\mathrm{Zn}}(C-2 B-1)
\end{aligned}
$$

where $A=\left(a_{0}-a_{\gamma}\right) / S_{\mathrm{a}}, B=R_{\mathrm{Mn}} / S_{\mathrm{Mn}}+R_{\mathrm{Zn}} / S_{\mathrm{Zn}}$, and $C=$ $2.84 R_{\mathrm{Mn}} / S_{\mathrm{Mn}}+1.80 R_{\mathrm{Zn}} / S_{\mathrm{Zn}}$.

The discussion described above can be extended also to the solid solutions which contain some other minor constituents replaced in the lattice.

\section{Experimental}

\section{Samples}

Seven synthetic powder samples shown in Table 1 were used.

\section{Chemical analysis}

Determination of $\mathrm{Fe}(\mathrm{II})$ and $\mathrm{Fe}(\mathrm{III})^{2} \quad$ A sample was decomposed with $\mathrm{H}_{2} \mathrm{SO}_{4}(1+1)$ and $\mathrm{HF}(46 \%)$ in $\mathrm{CO}_{2}$ atmosphere. After being mixed with a boric acid solution, it was titrated with a $\mathrm{KMnO}_{4}$ standard solution to determine $\mathrm{Fe}(\mathrm{II})$ in the same atmosphere. After reduction of $\mathrm{Fe}(\mathrm{III})$ to $\mathrm{Fe}(\mathrm{II})$ in a zinc-amalgam reductor, the sample solution was titrated with the same $\mathrm{KMnO}_{4}$ standard solution to determine the amount of total iron, from which the amount of $\mathrm{Fe}$ (III) was calculated as total iron minus divalent iron. The analyses were carried out after careful training using mixed solutions of $\left(\mathrm{NH}_{4}\right)_{2} \mathrm{Fe}\left(\mathrm{SO}_{4}\right)_{2}$ and $\left(\mathrm{NH}_{4}\right)_{2} \mathrm{Fe}_{2}\left(\mathrm{SO}_{4}\right)_{4}$.

Determination $\mathrm{Mn}^{\prime \theta}$ and $\mathrm{Zn}^{11}$ A sample was decomposed with a mixed acid of nitric, sulfuric, and phosphoric acids. After oxidation of manganese ions to permanganate with trace silver ions and ammonium peroxydisulfate, Mn was determined by spectrophotometry. Zinc was determined by atomic absorption spectroscopy, after the decomposition with hydrochloric and nitric acids.

\section{Measurements of lattice constants}

A Rigaku X-ray diffractometer equipped with an iron tube was used for the measurements of lattice constants under the conditions in Table 2. A sample of about $0.5 \mathrm{~g}$ was mixed with silicon powder of nominal $99.9 \%$ purity and 100 mesh as internal standard at the ratio of $2: 1$, packed in a standard sample holder and analyzed. The XRD lines of (511), (440), (533) or (731) from the solid solution to be analyzed and (311) or (422) from silicon standard as shown in Table 3 were recorded twice on a chart at a slow scanning rate. Each XRD angle was estimated from the center of gravity of a triangle approximating the line profile and corrected using the standard angle of the silicon to calculate the lattice constant.

\section{$X R F$ analysis}

A Philips PW1410 semiautomatic XRF spectrometer

Table 1 Samples and their analytical results (wt\%)

\begin{tabular}{lccccr}
\hline \multicolumn{1}{c}{ Sample } & $\mathrm{Fe}_{2} \mathrm{O}_{3}$ & $\mathrm{FeO}$ & $\mathrm{MnO}$ & $\mathrm{ZnO}$ & Total \\
\hline $\mathrm{A}:$ high-purity $\mathrm{Fe}_{3} \mathrm{O}_{4}, 99.9 \%$ & 75.1 & 24.8 & 0.00 & 0.00 & 99.9 \\
$\mathrm{~B}:$ reagent of $\mathrm{Fe}_{3} \mathrm{O}_{4}$ & 74.7 & 24.3 & 0.81 & 0.25 & 100.1 \\
$\mathrm{C}:$ reagent of $\mathrm{Fe}_{3} \mathrm{O}_{4}$ & 75.6 & 24.8 & 0.28 & 0.01 & 100.7 \\
$\mathrm{D}:$ needle-shaped magnetite & 84.2 & 13.3 & 0.27 & 0.87 & 98.6 \\
$\mathrm{D}^{\prime}$ : sample D kept at $110^{\circ} \mathrm{C}, 3 \mathrm{~h}$ & 87.8 & 10.2 & 0.27 & 0.87 & 99.1 \\
$\mathrm{E}:$ needle-shaped maghemite & 96.6 & 0.0 & 0.26 & 0.88 & 97.7 \\
$\mathrm{~F}:$ needle-shaped maghemite & 97.2 & 0.2 & 0.26 & 0.04 & 97.7 \\
\hline
\end{tabular}


Table 2 Conditions of XRD

\begin{tabular}{ll} 
Target & Fe \\
Voltage $/ \mathbf{k V}$ & 35 \\
Current/mA & 10 \\
Filter & $\mathrm{Mn}$ \\
d. and s. slit/deg & 1 \\
r. slit/mm & 0.3 \\
Time constant/s & 4 \\
Scanning speed/deg min & -1 \\
Chart speed $/ \mathrm{mm} \mathrm{min}$ min $^{-1}$ & $1 / 4$ \\
\hline
\end{tabular}

Table 3 XRD lines measured

\begin{tabular}{ccccc}
\hline \multicolumn{2}{c}{ Sample } & & \multicolumn{2}{c}{ Silicon (standard) } \\
\cline { 1 - 2 } \cline { 5 - 5 }$h k l$ & $2 \theta / \mathrm{deg}$ & & $h k l$ & $2 \theta / \mathrm{deg}$ \\
\hline 511 & $73.7-74.2$ & & 311 & 72.539 \\
440 & $81.5-82.1$ & & 422 & $121.675^{\mathrm{a}}$ \\
533 & $98.4-99.4$ & & & \\
731 & $125.1-126.2$ & & & \\
\hline
\end{tabular}

a. For $\mathrm{Fe} \mathrm{K}_{\boldsymbol{\alpha} \mathbf{l}}$. Others for $\mathrm{Fe} \mathrm{K}_{\boldsymbol{\alpha}}$.

Table 4 Conditions of measurements of XRF intensity ratios

\begin{tabular}{ll}
\hline Target & W \\
Voltage $/ \mathrm{kV}$ & 25 \\
Current $/ \mathrm{mA}$ & 4 \\
Anal. crystal & $\mathrm{LiF}$ \\
Path & vacuum \\
Collimator & fine \\
Detector & $\mathrm{FC}+\mathrm{SC}$ \\
Scanning speed $/ \mathrm{deg} \mathrm{min}^{-1}$ & $1 / 4$ \\
Time constant $/ \mathrm{s}$ & 4 \\
\hline
\end{tabular}

equipped with a tungsten tube was used for the qualitative analysis and the measurements of XRF intensity ratios of $\mathrm{Mn} \mathrm{K}_{\alpha} / \mathrm{Fe} \mathrm{K}_{\alpha}$ and $\mathrm{Zn} \mathrm{K}_{\alpha} / \mathrm{Fe} \mathrm{K}$. The sample powder of about $0.5 \mathrm{~g}$ was placed in a small bag made of $6 \mu \mathrm{m}$ Mylar film, and analyzed under the conditions of Table 4. In order to prevent counting losses arising from very high intensities of $\mathrm{Fe} \mathrm{K}_{\alpha}$, an aluminum filter $0.3 \mathrm{~mm}$ thick, attached to the apparatus, was inserted between the tube window and sample. The Fe $K_{\alpha}$ intensities without the filter were calculated by using the absorption coefficient of the filter measured with a smaller iron-containing sample.

\section{Results and Discussion}

\section{Qualitative and chemical analyses}

The results of the XRF analysis showed that the samples other than " $A$ " contained small amounts of $\mathrm{Mn}$ and $\mathrm{Zn}$, and trace amounts of $\mathrm{Cr}$ which were negligible for the discussion here. Table 1 shows results of chemi- cal analysis.

Relationships between $X R F$ intensity ratios and mole ratios of $\mathrm{MnO}$ and $\mathrm{ZnO}$ against $\left(2 \mathrm{Fe}_{2} \mathrm{O}_{3}+\mathrm{FeO}\right)$

Linear relationships were obtained between $\mathbf{M n ~} \mathbf{K}_{\alpha}$ / $\mathrm{Fe} \mathrm{K}_{\alpha}$ or $\mathrm{Zn} \mathrm{K}_{\alpha} / \mathrm{Fe} \mathrm{K}_{\alpha}$ intensity ratios and mole ratios of $\mathrm{MnO}$ or $\mathrm{ZnO}$ against $\left(2 \mathrm{Fe}_{2} \mathrm{O}_{3}+\mathrm{FeO}\right)$ with relative standard deviations (RSD) of $12 \%$ for $\mathrm{MnO}$ and $8 \%$ for $\mathrm{ZnO}$ at the mole ratio of 0.005 , as shown in Fig. 1 . The slopes, $S_{\mathrm{Mn}}$ and $S_{\mathrm{Zn}}$, of the regression lines for $\mathrm{Mn}$ and $\mathrm{Zn}$ were 1.63 and 0.87 , respectively.

\section{Relationship between composition and lattice constant of the} solid solutions

Figure 2 shows the relationship between the observed

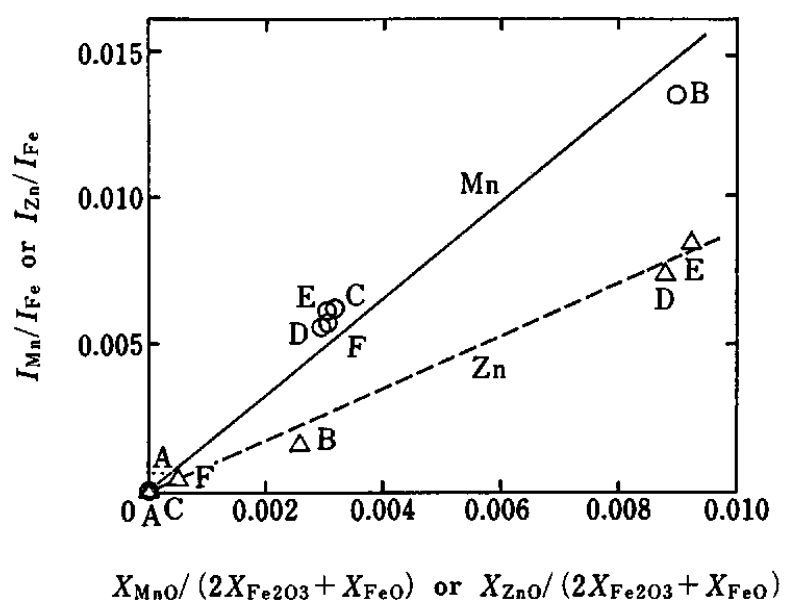

Fig. 1 Relationships between XRF intensity ratios and mole ratios of manganese or zinc oxides against iron oxides $\left(2 \mathrm{Fe}_{2} \mathrm{O}_{3}+\mathrm{FeO}\right)$. Equation for $\mathrm{MnO}: y=1.63 x, \sigma(x)=0.0006$ (12\% in RSD at $x=0.005)$; for ZnO: $y=0.87 x, \sigma(x)=0.0004$ ( $8 \%$ in RSD at $x=0.005$ ).

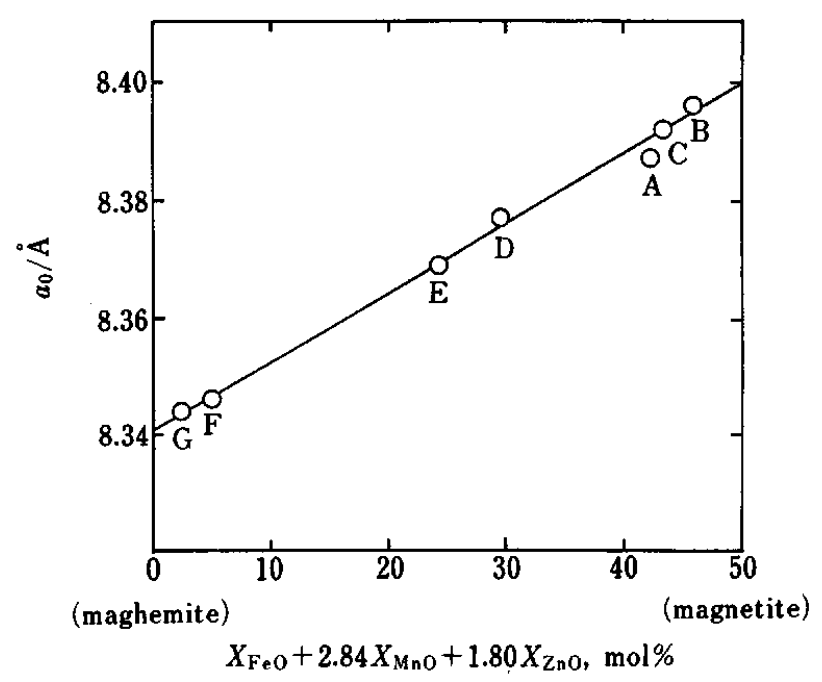

Fig. 2 Relationship between observed lattice constant $\left(a_{0}\right)$ and sum total of converted mole percentages of divalent metal oxides $\left(X_{\mathrm{FeO}}+2.84 X_{\mathrm{MnO}}+1.8 X_{\mathrm{ZnO}}\right) . \quad y=8.342+$ $0.001135 x, \sigma(x)=1.6 \mathrm{~mol} \%$. 
Table 5 Comparison between the results of wet and X-ray analyses

\begin{tabular}{|c|c|c|c|c|c|c|c|c|}
\hline \multirow{2}{*}{ Sample } & \multicolumn{2}{|c|}{$\mathrm{Fe}_{2} \mathrm{O}_{3}, \mathrm{~mol} \%$} & \multicolumn{2}{|c|}{$\mathrm{FeO}, \mathrm{mol} \%$} & \multicolumn{2}{|c|}{$\mathrm{MnO}, \mathrm{mol} \%$} & \multicolumn{2}{|c|}{$\mathrm{ZnO}, \mathrm{mol} \%$} \\
\hline & Wet & X-Ray & Wet & X-Ray & Wet & X-Ray & Wet & X-Ray \\
\hline $\mathbf{A}$ & 57.7 & 60.3 & 42.3 & 39.7 & 0.00 & 0.00 & 0.00 & 0.00 \\
\hline B & 57.0 & 58.6 & 41.2 & 39.9 & 1.39 & 1.29 & 0.37 & 0.29 \\
\hline $\mathrm{C}$ & 57.5 & 56.8 & 42.0 & 42.6 & 0.48 & 0.59 & 0.01 & 0.00 \\
\hline $\mathrm{D}$ & 72.5 & 70.6 & 25.5 & 27.3 & 0.53 & 0.58 & 1.47 & 1.44 \\
\hline $\mathrm{E}$ & 97.6 & 97.4 & 0.0 & 0.0 & 0.59 & 0.73 & 1.75 & 1.90 \\
\hline $\mathbf{F}$ & 98.9 & 98.3 & 0.4 & 1.0 & 0.60 & 0.69 & 0.08 & 0.09 \\
\hline
\end{tabular}

lattice constants $a_{0}$ and the total mole percentage as $\mathrm{FeO}$, which was shown by $\left(X_{\mathrm{FeO}}+c_{\mathrm{MnO}} X_{\mathrm{MnO}}+c_{\mathrm{ZnO}} X_{\mathrm{ZnO}}\right)$ in Eq. (2). The regression line was expressed by the formula: $y=8.342+0.001135 x, \sigma(x)=1.6 \mathrm{~mol} \%$, which can be universally used for the analysis of the solid solution.

\section{Comparison between analytical results by the present and wet methods}

The observed values of $R_{\mathrm{Mn}}, R_{\mathrm{Zn}}$ and $a_{0}$ were substituted in Eqs. (6) - (9) to obtain mole percentages of the constituents. Table 5 shows analytical results, which are given as mole percentages for convenience in construction of chemical formulas. The differences between the values obtained by the two methods were within $2.6 \mathrm{~mol} \%$ or $3.4 \mathrm{wt} \%$ (4.5\% in relative error) for $\mathrm{Fe}_{2} \mathrm{O}_{3}$, within $2.6 \mathrm{~mol} \%$ or $1.5 \mathrm{wt} \%(6.2 \%$ in relative error) for $\mathrm{FeO}$, and within $0.15 \mathrm{~mol} \%$ or $0.08 \mathrm{wt} \%$ for $\mathrm{MnO}$ and $\mathrm{ZnO}$, which were minor constituents. These relative errors or differences are negligible for the construction of their chemical formulas. The present method is nondestructive and does not include any painstaking procedures such as those needed in the wet analysis. Time required for a complete analysis of a sample is about $30 \mathrm{~min}$, including the calculation time.

\section{References}

1. T. Fukasawa, M. Iwatsuki and M. Furukawa, submitted to Anal. Chim. Acta.

2. I. Iwasaki, T. Katsura, M. Yoshida and T. Tarutani, Bunseki Kagaku, 6, 211 (1957).

3. J. Kanazawa, H. Maekawa and T. Yokogawa, " $X$-sen Bunseki no Shimpo (Adv. in X-ray Anal., Japan)”, 13, 9 (1982).

4. K. Nomura, Y. Ujihira, K. Itoh and K. Honda, Thin Solid Films, 128, 225 (1985).

5. M. Fujinami and Y. Ujihira, Hyperfine Int., 29, 1475 (1986).

6. JCPDS $19-629,1969$.

7. JCPDS $25-1402,1975$.

8. JCPDS $10-319,1960$.

9. JCPDS $22-1012,1972$.

10. Nippon Gakujutsu Shinkoukai (The Japan Association for the Advancement of Science), "Tekkou Kagaku Bunseki Zensho (Chemical Analysis of Iron and Steel: A Comprehensive Treatment, in Japanese)", new ed., Vol. 9, p. 38, Nikkan Kougyou Shimbunsha, Tokyo, 1963.

11. JIS M 8124, "Methods for Determination of Zinc in Ores", Japanese Industrial Standards Committee, Tokyo, 1979.

(Received August 14, 1992) (Accepted November 24, 1992) 